\title{
Safety, efficacy, and cost-effectiveness of intraoperative blood salvage in OPCABG with different amount of bleeding: a single- center, retrospective study
}

\author{
Huan Wang, Weijian Zheng, Weiping Fang, Gaige Meng, Lei Zhang, Yannan Zhou, Erwei Gu and Xuesheng Liu*
}

\begin{abstract}
Background: We sought to evaluate the safety, efficacy, and cost-effectiveness of intraoperative blood salvage (IBS) in off-pump coronary artery bypass grafting (OPCABG) surgery with different amount of bleeding.

Methods: We retrospectively reviewed the medical records of 321 patients who underwent OPCABG between December 2012 and December 2016 at our hospital. Patients treated with IBS or allogeneic blood (AB) transfusions were divided into three groups depending on the amount of bleeding respectively: IBS1 or $A B 1$ group (400-600 ml); IBS2 or AB2 group (600-1000 ml); IBS3 or AB3 group (1000-1500 ml). The intraoperative and postoperative conditions, blood transfusion volume, clinical and hematological outcomes, and total blood transfusion cost were examined.

Results: The amount of allogeneic red blood cell (RBC) transfusion in the IBSs groups were significantly lower than that in the ABs groups $(P<0.01)$. Furthermore, drainage volume $24 \mathrm{~h}$ post-surgery $(P<0.05)$ and white blood cell count $(W B C) 2$ day post-surgery $(P<0.01)$ in IBS3 group were significantly higher compared with the AB3 group. Additionally, when IBS cost was 230 USD per set, the total blood transfusion cost in the IBSs groups was significantly higher than that in the ABs groups $(P<0.01)$; however, when 199 or 184 USD, only the IBS1 group, rather than IBS2 or IBS3, showed significantly higher cost of the total blood transfusion compared with the $A B 1$ group $(P<0.05)$.

Conclusions: When the amount of bleeding was 600-1000 ml, IBS can significantly reduce the demand for allogeneic blood, and has no direct adverse effects on coagulation function and recuperation, and is costeffective in OPCABG.
\end{abstract}

Keywords: OPCABG, Autologous blood transfusion, Cost-effectiveness

\section{Background}

Increased intraoperative blood loss has been shown in off-pump coronary artery bypass grafting (OPCABG) due to the fact that patients with a high risk of bleeding try to receive surgery [1-3]. Despite the progress in the safety of allogeneic blood $(\mathrm{AB})$ transfusions, there are still some potential risks such as immunological reactions, transfusion-transmitted infection, and bacteria contamination $[4,5]$. Intraoperative blood salvage (IBS),

\footnotetext{
* Correspondence: liuxuesheng@ahmu.edu.cn

Department of Anesthesiology, the First Affiliated Hospital of Anhui Medical University, No. 218 Jixi Road, Hefei, Anhui 230022, People's Republic of China
}

also known as autologous blood transfusion or cell salvage, is a medical procedure of collecting, filtering and washing blood gathered from the surgical field to produce autologous blood for transfusion back to the patient [1]. In order to reduce the incidence of adverse events resulting from $A B$ transfusion and to cope with increasing blood shortage and medical costs, IBS has been recently applied in the field of cardiac surgery.

With the progress in surgical technique and the application of advanced equipment, on one hand, the amount of intraoperative bleeding was obviously reduced due to the development of minimally invasive surgery [6]; and

(C) The Author(s). 2018 Open Access This article is distributed under the terms of the Creative Commons Attribution 4.0 International License (http://creativecommons.org/licenses/by/4.0/), which permits unrestricted use, distribution, and 
on the other hand, the amount of intraoperative blood loss is still fluctuating as many patients with high bleeding risk also began to undergo surgical treatment. The cost-effectiveness of IBS differs with the amount of bleeding. Until now, few data evaluating IBS in highbleeding-risk cardiac surgery has published [7].

Thus, the aim of this study was to evaluate the safety, efficacy, and cost-effectiveness of IBS in OPCABG surgery with different amount of bleeding. To address this, we retrospectively analyzed the medical records of $321 \mathrm{pa}-$ tients who underwent OPCABG at our hospital. Patients treated with $\mathrm{IBS}$ or $\mathrm{AB}$ transfusions were divided into three groups depending on the amount of bleeding respectively. The intraoperative and postoperative conditions, blood transfusion volume, clinical and hematological outcomes, and total blood transfusion cost were examined.

\section{Methods}

\section{Subjects}

We retrospectively reviewed the medical records of 321 patients undergoing elective OPCABG surgery under general anesthesia from December 2012 to December 2016 in the First Affiliated Hospital of Anhui Medical University. Of all, there were 206 males and 115 females, with age of 50-75 years, body mass index (BMI) of 1634, and the American Society of Anesthesiologists' (ASA) physical status of II-IV level. A previous study has indicated that the application of IBS is more meaningful in patients with more than $1000 \mathrm{ml}$ blood loss during surgery [1] $]^{\cdot}$ Nevertheless, at present, the intraoperative blood loss is usually less than $1000 \mathrm{ml}$, and Advanced Trauma Life Support System (ATLS) [8] believe that human conditions are stable only when the blood loss was less than 15\% (about $600 \mathrm{ml}$ when calculating with a systemic blood volume of $4000 \mathrm{ml}$ ). In clinical applications, we found that when the bleeding volume was less than $600 \mathrm{ml}$, Cell Saver, in most cases, washed out autologous red blood cells with lower hematocrit, and the application efficiency was poor; when the bleeding volume was less than $400 \mathrm{ml}$, blood transfusion was usually not needed. Therefore, for patients who underwent IBS, they were divided into IBS1 group (bleeding volume 400-600 ml), IBS2 group (600-1000 ml), IBS3 group $(1000-1500 \mathrm{ml})$ depending on the amount of intraoperative blood loss. Patients with allogeneic blood transfusions blood were divided into AB1 group (bleeding volume 400-600 ml), AB2 group (600-1000 ml), AB3 group (1000-1500 ml).

The exclusion criteria were as follows: (1) cases of abandoning treatment and self-discharge due to the personal wishes of patients and their families; (2) cases of secondary surgery; (3) cases of severe data loss; (4) cases in which the amount of intraoperative blood loss failed to meet the criteria.
The study was approved by the Ethics Committee of the First Affiliated Hospital of Anhui Medical University. Written informed consent was obtained from each patient. The CONSORT diagram of the flow of patients was summarized in Fig. 1.

\section{Surgery and blood transfusion}

All patients received intratracheal intubation and combined intravenous with inhalation general anesthesia in each case, the red blood cell salvage was performed using a Cell Saver 5 System (Haemonetics; Braintree, MA). Normal saline $(500 \mathrm{ml})$ containing $15,000 \mu \mathrm{l}$ heparin was used as the anticoagulant solution. The blood reservoir and tubing are pre-impregnated with $150 \mathrm{ml}$ anticoagulant solution before the start of blood recovery. The drip rate was 1 to 2 per second depending on the speed of blood flow during machine operation. After filtrated, centrifugated, washed, the recovered blood became autologous blood (autologous RBC) with a hematocrit of $50 \%$ to $60 \%[9,10]$, and was then transfused back to the patients immediately. All autologous $\mathrm{RBC}$ was transfused back before the end of surgery. Blood transfusions were administrated if hemoglobin (HGB) level $<9$ g per deciliter. HBG level was maintained at $\geq 10 \mathrm{~g}$ per deciliter [11]. In order to prevent coagulation dysfunction, fresh frozen plasma and platelets were transfused according to thromboelastogram data and the clinician experience when necessary.

\section{Charges}

The costs in the ABs group are the sum of the costs of all infusion of allogeneic blood products, including allogeneic red blood cells, fresh frozen plasma and other costs. Each unit of allogeneic red blood cells was 34 USD; fresh frozen plasma per $100 \mathrm{ml}$ was 6 USD; Each dose of therapeutic platelets was 218 USD; Each unit of cold precipitation was 15 USD.

The costs in the IBSs group include cell saver consumables usage fees and allogeneic blood products costs. Each set of consumables includes a collection reservoir, a combination line, a centrifuge cup, a reinfusion bag, and a waste bag. Due to the reduction of costs, the cost of cell saver consumables has been declined year by year. Here, the cost of cell saver was divided into three grades, 230, 199 and 184 USD, which were due to the different prices of cell saver consumables in different periods. Patients in the IBSs group were treated with a recovery autologous blood transfusion technique, which only charged the consumables usage fee, and did not charge the technical and labor costs of the IBS. If a patient in the IBS group receives an allogeneic blood product, it is also charged according to the cost of the allogeneic blood products. 


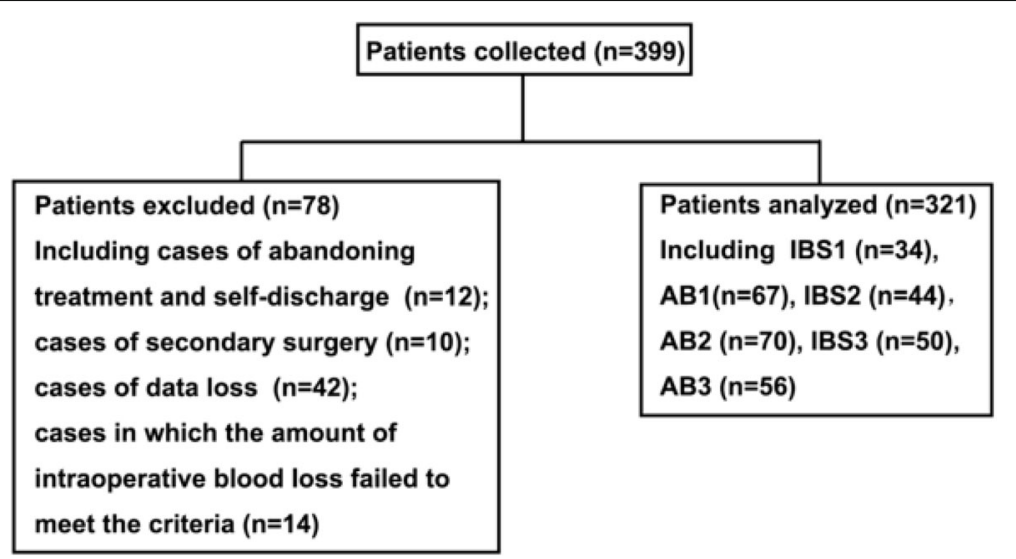

Fig. 1 CONSORT diagram of the flow of patients

\section{Data collection}

The main indicators included intraoperative blood loss, hemoglobin (HGB), white blood cell count (WBC), RBC, platelet (PLT) values before and 1, 2, and 7 days after surgery, infusion of allogeneic RBC, PLT, and plasma, and total transfusion costs. The minor indicators included mechanical ventilation duration, intensive care unit (ICU) stay, hospital stay, etc. The intraoperative blood loss is estimated by calculating the sum of the blood in the vacuum aspirator, the blood in the autoblood reservoir, the gauze, and the blood in the cotton pad.

\section{Statistical analysis}

All statistical analyses were performed using SPSS statistical software package standard version 17.0 (SPSS, Inc., Chicago, IL, USA). Normally distributed data are expressed as the mean \pm standard deviation (SD). Two independent sample $t$-tests were used for comparison between groups. $X^{2}$-tests were used for comparison of counting data. $P<$ 0.05 was considered to indicate a statistically significant difference.

\section{Results}

\section{General conditions of all subjects}

As shown in Table 1, there was no significant difference in gender, age, ASA status, cardiac function, and complications including hypertension and diabetes of all the 321 participants.

\section{Comparison of intraoperative and postoperative conditions as well as blood transfusions}

As shown in Tables 2 and 3, there were no significant differences between the ABs and IBSs groups in terms of intraoperative and postoperative conditions in patients, including the number of intra-aortic balloon pump counterpulsation (IABP), number of bridges, operation duration, hospital stay, ICU stay, mechanical ventilation duration, Intraoperative blood loss, total platelet transfusion at therapeutic dose, and total plasma transfusion. As indicated in Table 3, the drainage volume $24 \mathrm{~h}$ post-surgery in the IBS3 group was significantly higher than that in the AB3 group $(P<0.05)$. Furthermore, the total infusion of allogeneic red blood cells in the IBSs groups was significantly lower than that in the corresponding ABs groups $(P<0.01)$.

\section{Comparison of hematological outcomes}

Next, we compared hematological outcomes of all the patients. Data revealed that the white blood cell count (WBC) 2 day post-surgery in the IBS3 group was significantly higher compared with the AB3 group (Table $4, P<0.01$ ).

Table 1 Comparison of general data

\begin{tabular}{|c|c|c|c|c|c|c|c|c|}
\hline Group & $\mathrm{N}$ & Male/Female (N) & Age & $\mathrm{BMI}\left(\mathrm{kg} / \mathrm{m}^{2}\right)$ & ASA II/III/IV & Cardiac function II/III/IV & Hypertension (\%) & Diabetes (\%) \\
\hline $\mathrm{IBS1}$ & 34 & $21 / 13$ & $64.82 \pm 6.25$ & $23.31 \pm 3.36$ & $13 / 20 / 1$ & $14 / 19 / 1$ & $18(53)$ & $8(24)$ \\
\hline $\mathrm{AB} 1$ & 67 & $34 / 33$ & $62.73 \pm 7.04$ & $23.76 \pm 3.45$ & $22 / 43 / 2$ & $24 / 41 / 2$ & $25(40)$ & $14(22)$ \\
\hline IBS2 & 44 & $24 / 20$ & $62.82 \pm 9.45$ & $23.79 \pm 3.75$ & $12 / 32 / 0$ & $18 / 26 / 0$ & $24(55)$ & $9(21)$ \\
\hline$A B 2$ & 70 & $45 / 25$ & $63.97 \pm 6.48$ & $22.96 \pm 3.37$ & $17 / 52 / 1$ & $25 / 44 / 1$ & $42(60)$ & $13(19)$ \\
\hline IBS3 & 50 & $33 / 17$ & $65.22 \pm 8.91$ & $24.32 \pm 3.67$ & $10 / 37 / 3$ & $16 / 31 / 3$ & $30(60)$ & $11(22)$ \\
\hline AB3 & 56 & $39 / 17$ & $63.41 \pm 7.96$ & $23.12 \pm 3.39$ & $11 / 43 / 2$ & $18 / 36 / 2$ & 27 (48) & $14(25)$ \\
\hline
\end{tabular}

$B M I$ body mass index, $A S A$ the American Society of Anesthesiologists' physical status 
Table 2 Comparison of intraoperative and postoperative conditions in patients

\begin{tabular}{llllllll}
\hline Group & N & IABP (\%) & Number of bridges & Operation duration $(\mathrm{min})$ & Hospital stay (day) & ICU stay (h) & Mechanical ventilation duration (h) \\
\hline IBS1 & 34 & $9(27)$ & $3.44 \pm 1.23$ & $225.41 \pm 47.45$ & $26.88 \pm 9.17$ & $55.35 \pm 62.97$ & $13.09 \pm 4.94$ \\
AB1 & 67 & $28(44)$ & $3.25 \pm 0.84$ & $239.87 \pm 32.46$ & $28.35 \pm 9.03$ & $62.97 \pm 30.24$ & $13.71 \pm 5.07$ \\
IBS2 & 44 & $15(34)$ & $3.66 \pm 0.88$ & $272.55 \pm 47.71$ & $28.45 \pm 7.89$ & $70.20 \pm 35.08$ & $14.75 \pm 5.28$ \\
AB2 & 70 & $22(31)$ & $3.47 \pm 1.05$ & $259.50 \pm 47.70$ & $27.00 \pm 8.14$ & $70.00 \pm 38.29$ & $13.91 \pm 5.94$ \\
IBS3 & 50 & $23(46)$ & $3.74 \pm 0.77$ & $283.00 \pm 50.02$ & $27.54 \pm 8.10$ & $73.66 \pm 34.30$ & $15.98 \pm 4.51$ \\
AB3 & 56 & $20(36)$ & $3.63 \pm 1.03$ & $284.52 \pm 38.15$ & $27.34 \pm 8.56$ & $67.34 \pm 38.87$ & $15.32 \pm 8.00$ \\
\hline
\end{tabular}

IABP intra-aortic balloon pump counterpulsation, ICU intensive care unit

\section{Comparison of total blood transfusion cost}

As reflected in Table 5, the total blood transfusion cost in the IBSs groups was significantly higher than that in the ABs groups when the IBS cost was 230 USD per set $(P<0.05)$. However, when 199 or 184 USD per set, only the IBS1, rather than IBS2 or IBS3 group, showed significantly higher cost of the total blood transfusion compared with the AB1 group $(P<0.05)$.

\section{Discussion}

Previous studies have shown that infusion of allogeneic blood has adverse effects on the long-term prognosis of patients $[12,13]$, especially for patients with existing cardiac problems, which can increase the mortality within 5 years after surgery [14]. At the same time, autologous blood transfusion has been recently used in the field of cardiac surgery due to the tight blood supply. However, the blind application of IBS technology will not only fail to exert its advantages, but also increase hospitalization costs and increase the burden on patients. Accordingly, in this study, a single OPCABG surgery was conducted, and bleeding was divided into three different hemorrhage layers to evaluate the impact of IBS on outcomes following OPCABG surgery.

The results showed that when the blood loss ranged from 600 to $1000 \mathrm{ml}$, the application of IBS led to a significant reduction in the transfusion volume of allogeneic blood. Meanwhile, IBS maintained the HGB and RBC values similar to that of the ABs groups. Moreover, IBS did not increase the number of postoperative leukocytes and drainage volume $24 \mathrm{~h}$ post-surgery. Additionally, IBS did not affect the mechanical ventilation duration, ICU stay, hospital stay, and total transfusion cost, showing the best cost-effectiveness.

Our results also revealed that, when the amount of blood loss ranged from 400 to $600 \mathrm{ml}$, IBS could reduce the total allogeneic $\mathrm{RBC}$ infusion to a certain degree. We also found that IBS significantly increased the total transfusion cost compared with the transfusion of allogeneic blood only. In addition, the current standards for blood transfusion for cardiac patients differs depending on the specific conditions, and the comparison of restrictive and loose blood transfusion standards are still to be studied [15]. Therefore, whether or not a patient with less than $600 \mathrm{ml}$ blood loss applies IBS can depend on the condition of the patient and the experience of clinicians.

When the blood loss ranged from 1000 to $1500 \mathrm{ml}$, the IBS3 group showed higher $24 \mathrm{~h}$ post-surgery drainage volume compared with the AB3 group but there was no significant difference in the number of postoperative platelets counts between the two groups. This may be attributed to less infusion of fresh frozen plasma and thus lack of coagulation factors. The results also showed that the IBSs groups had lower plasma transfusion volume than in the ABs groups, indicating that the application of the IBS technique requires a reasonable amount of infusion of blood products such as fresh frozen plasma rich in coagulation factors when the amount of intraoperative blood loss is large, otherwise it may affect the coagulation function of patients. This is consistent with the results of Shen et al. [16]. The cause of this

Table 3 Comparison of bleeding and blood transfusion in patients

\begin{tabular}{lllllll}
\hline Group & $N$ & $\begin{array}{l}\text { Intraoperative blood } \\
\text { loss }(\mathrm{ml})\end{array}$ & $\begin{array}{l}\text { Drainage volume 24 h post- } \\
\text { surgery }(\mathrm{ml})\end{array}$ & $\begin{array}{l}\text { Allogeneic red blood cell } \\
\text { transfusion }(\mathrm{U})\end{array}$ & $\begin{array}{l}\text { Total platelet transfusion } \\
\text { (therapeutic dose) }\end{array}$ & $\begin{array}{l}\text { Total plasma } \\
\text { transfusion }(\mathrm{ml})\end{array}$ \\
\hline IBS1 & 34 & $476.94 \pm 96.75$ & $470.15 \pm 154.01$ & $1.97 \pm 1.98^{\mathrm{b}}$ & $0.00 \pm 0.00$ & $426.47 \pm 260.31$ \\
AB1 & 67 & $447.49 \pm 110.86$ & $469.08 \pm 174.37$ & $4.7 \pm 1.73$ & $0.02 \pm 0.13$ & $518.36 \pm 291.45$ \\
IBS2 & 44 & $796.05 \pm 99.58$ & $474.95 \pm 129.14$ & $1.86 \pm 2.73^{\mathrm{b}}$ & $0.02 \pm 0.15$ & $479.55 \pm 383.72$ \\
AB2 & 70 & $789.77 \pm 100.22$ & $511.57 \pm 170.90$ & $5.19 \pm 2.76$ & $0.06 \pm 0.23$ & $596.43 \pm 404.35$ \\
IBS3 & 50 & $1393.26 \pm 270.87$ & $626.16 \pm 189.38^{\mathrm{a}}$ & $3.78 \pm 4.60^{\mathrm{b}}$ & $0.08 \pm 0.27$ & $738.00 \pm 688.87$ \\
AB3 & 56 & $1331.80 \pm 276.39$ & $543.32 \pm 185.71$ & $6.52 \pm 4.11$ & $0.07 \pm 0.26$ & $882.14 \pm 465.87$ \\
\hline
\end{tabular}

${ }^{\mathrm{a}} P<0.05,{ }^{\mathrm{b}} P<0.01$ vs. AB group 
Table 4 Comparison of hematological outcomes

\begin{tabular}{|c|c|c|c|c|c|c|}
\hline Indexes & Group & $\mathrm{N}$ & Pre-surgery & $1 \mathrm{~d}$ post-surgery & $2 \mathrm{~d}$ post-surgery & $7 \mathrm{~d}$ post-surgery \\
\hline \multirow[t]{6}{*}{$\mathrm{HGB}(\mathrm{g} / \mathrm{L})$} & IBS1 & 34 & $126.41 \pm 12.03$ & $123.41 \pm 15.51$ & $119.24 \pm 16.86$ & $124.65 \pm 19.05$ \\
\hline & $\mathrm{AB1}$ & 67 & $127.57 \pm 11.38$ & $124.90 \pm 12.48$ & $119.24 \pm 12.30$ & $127.81 \pm 73.53$ \\
\hline & IBS2 & 44 & $131.43 \pm 11.78$ & $123.86 \pm 13.98$ & $118.55 \pm 17.12$ & $125.30 \pm 17.25$ \\
\hline & AB2 & 70 & $129.97 \pm 13.09$ & $124.57 \pm 13.21$ & $120.11 \pm 14.66$ & $130.17 \pm 16.72$ \\
\hline & IBS3 & 50 & $134.54 \pm 13.16$ & $115.62 \pm 19.41$ & $113.22 \pm 14.18$ & $126.18 \pm 14.13$ \\
\hline & AB3 & 56 & $137.14 \pm 13.07$ & $118.71 \pm 13.02$ & $116.91 \pm 15.12$ & $129.32 \pm 16.03$ \\
\hline \multirow[t]{6}{*}{$\operatorname{WBC}\left(10^{9} / \mathrm{L}\right)$} & IBS1 & 34 & $6.39 \pm 1.43$ & $14.43 \pm 4.00$ & $13.99 \pm 4.54$ & $8.99 \pm 2.42$ \\
\hline & $A B 1$ & 67 & $6.18 \pm 1.64$ & $13.98 \pm 3.67$ & $12.98 \pm 4.29$ & $9.62 \pm 2.62$ \\
\hline & IBS2 & 44 & $6.59 \pm 1.49$ & $15.52 \pm 4.43$ & $14.54 \pm 3.70$ & $9.45 \pm 2.83$ \\
\hline & $A B 2$ & 70 & $6.73 \pm 1.57$ & $14.52 \pm 3.59$ & $13.17 \pm 4.66$ & $9.97 \pm 2.82$ \\
\hline & IBS3 & 50 & $6.62 \pm 1.76$ & $14.06 \pm 3.92$ & $15.08 \pm 5.07^{b}$ & $10.63 \pm 4.45$ \\
\hline & AB3 & 56 & $6.83 \pm 1.78$ & $13.53 \pm 3.55$ & $12.53 \pm 3.53$ & $9.79 \pm 2.77$ \\
\hline \multirow[t]{6}{*}{$\operatorname{RBC}\left(10^{12} / L\right)$} & IBS1 & 34 & $4.17 \pm 0.53$ & $4.06 \pm 0.44$ & $3.91 \pm 0.50$ & $4.11 \pm 0.55$ \\
\hline & $A B 1$ & 67 & $4.23 \pm 0.38$ & $4.16 \pm 0.41$ & $3.94 \pm 0.43$ & $4.20 \pm 0.53$ \\
\hline & IBS2 & 44 & $4.29 \pm 0.48$ & $4.07 \pm 0.48$ & $3.87 \pm 0.56$ & $4.19 \pm 0.64$ \\
\hline & AB2 & 70 & $4.30 \pm 0.45$ & $4.08 \pm 0.39$ & $3.92 \pm 0.47$ & $4.21 \pm 0.53$ \\
\hline & IBS3 & 50 & $4.36 \pm 0.45$ & $3.80 \pm 0.39$ & $3.56 \pm 0.39$ & $4.10 \pm 0.41$ \\
\hline & AB3 & 56 & $4.51 \pm 0.41$ & $3.97 \pm 0.43$ & $3.65 \pm 0.51$ & $4.18 \pm 0.60$ \\
\hline \multirow[t]{6}{*}{$\operatorname{PLT}\left(10^{9} / \mathrm{L}\right)$} & IBS1 & 34 & $200.15 \pm 65.35$ & $191.68 \pm 72.16$ & $152.76 \pm 58.65$ & $209.12 \pm 65.99$ \\
\hline & $A B 1$ & 67 & $213.25 \pm 65.21$ & $167.84 \pm 55.63$ & $135.76 \pm 73.53$ & $203.24 \pm 73.53$ \\
\hline & IBS2 & 44 & $212.45 \pm 57.45$ & $184.39 \pm 61.64$ & $156.68 \pm 69.92$ & $212.30 \pm 97.22$ \\
\hline & $A B 2$ & 70 & $219.91 \pm 71.88$ & $184.43 \pm 55.13$ & $150.47 \pm 54.44$ & $220.09 \pm 80.20$ \\
\hline & IBS3 & 50 & $212.26 \pm 50.83$ & $172.58 \pm 57.43$ & $142.82 \pm 52.47$ & $236.44 \pm 97.12$ \\
\hline & AB3 & 56 & $208.68 \pm 61.78$ & $156.20 \pm 38.59$ & $137.63 \pm 47.12$ & $213.23 \pm 91.22$ \\
\hline
\end{tabular}

$H G B$ hemoglobin, WBC white blood cell count, RBC red blood cell count, $P L T$ platelet ${ }^{\mathrm{b}} P<0.01$ vs. $A B$ group

phenomenon may also include an increase in autologous blood transfusion, which dilutes blood coagulation factors and platelets, increases the heparin content that enters the body [17], thereby promoting damage to the coagulation system. Furthermore, the number of white blood cells in the IBS3 group was higher than that in the $\mathrm{AB} 3$ group on the second postoperative day. In addition, we found the $\mathrm{WBC}$ value 2 day post-surgery was in the

Table 5 Comparison of the total blood transfusion cost

\begin{tabular}{|c|c|c|c|c|}
\hline \multirow[t]{2}{*}{ Group } & \multirow[t]{2}{*}{ N } & \multicolumn{3}{|c|}{ Total blood transfusion cost (USD) } \\
\hline & & 230 & 199 & 184 \\
\hline IBS1 & 34 & $327.5 \pm 96.9^{a}$ & $297.0 \pm 96.9^{a}$ & $281.7 \pm 96.9^{a}$ \\
\hline$A B 1$ & 67 & $233.7 \pm 107.9$ & $233.7 \pm 107.9$ & $233.7 \pm 107.9$ \\
\hline IBS2 & 44 & $333.8 \pm 145.1^{\mathrm{a}}$ & $303.2 \pm 145.1$ & $287.9 \pm 145.1$ \\
\hline $\mathrm{AB} 2$ & 70 & $260.9 \pm 157.5$ & $260.9 \pm 157.5$ & $260.9 \pm 157.5$ \\
\hline IBS3 & 50 & $439.2 \pm 276.2^{a}$ & $408.6 \pm 276.2$ & $393.3 \pm 276.2$ \\
\hline AB3 & 56 & $332.3 \pm 219.8$ & $332.3 \pm 219.8$ & $332.3 \pm 219.8$ \\
\hline
\end{tabular}

${ }^{\mathrm{a}} P<0.05$ vs. AB group
IBS3 group was significantly higher compared with the AB3 group which is different from the findings of Cui et al. [18]. The different results may be attributed to several factors, including less blood loss $(700 \pm 50 \mathrm{ml})$, and reduced blood transfusion volume, and the different type of surgery in the study by Cui et al. Currently used autologous blood transfusion apparatus can destroy cell components during blood recovery and centrifugation, activate platelets and leukocytes. Conventional washing fails to completely remove activated leukocytes, so reinfusion into patients can promote the release of inflammatory mediators and further aggravated the systemic inflammatory response. Clinically, WBC is widely used for the auxiliary diagnosis of infection, and the degree of WBC elevation is directly related to the degree of trauma [19]. IBS may retain more white blood cells and inflammatory mediators compared with allogeneic blood products with leukocyte-depleted red blood cells. Therefore, the addition of a leukocyte filter would be more beneficial to patients when using IBS in high-bleedingrisk cardiac surgery [20]. 
Moreover, we also observed that the total blood transfusion cost in the IBSs groups was significantly higher than that in the ABs groups when the IBS cost was 230 USD per set. However, when 199 or 184 USD per set, the IBS1 group showed significantly higher cost of the total blood transfusion compared with the AB1 group. With the reduction of IBS charges and the increase of the blood loss amount, the cost-effectiveness of IBS has gradually emerged. Xie et al. [21] demonstrated that the use of IBS in OPCABG surgery reduced the chances of patients exposure to allogeneic blood, decreased the incidence of transfusion-related diseases and transfusion reactions, but it increased the total transfusion costs. Attaran et al. [22] also stated that the routine use of IBS is not cost-effective. Malhotra et al. [1] proposed that the application of IBS is more meaningful in patients with more than $1000 \mathrm{ml}$ blood loss during surgery. Wang et al. [23] reported that a cell saver may be beneficial only when it is used for shed blood and/or residual blood or during the entire operative period. Processing cardiotomy suction blood with a cell saver only during cardiopulmonary bypass has no significant effect on blood conservation and increases fresh frozen plasma transfusion. These abovementioned findings are $\mathrm{s}$ not exactly the same as our findings. This may be attributed to the large difference in charges for IBS and allogenic blood products between at home and abroad, as well as the higher charge of IBS and the low cost of allogeneic blood products at home. In addition, the decrease in intraoperative blood loss or inappropriate use of blood transfusion apparatus results in less autologous blood recovery and even failure to wash autologous blood, which may also affect the cost. Moreover, the limited sample size in this study should also be noted. We propose that the results of cost-benefit analysis may differ when the bleeding amount is higher or the IBS charge is lower.

This study was a retrospective analysis, in which patients in the IBS group were started to use autologous blood transfusions immediately after surgery. Due to the inability to predict intraoperative blood loss, we used the commonly used loose blood transfusion standard. That is, when the patient's HGB value was $<9 \mathrm{~g} / \mathrm{L}$, blood transfusion can be started. In addition, it is necessary to refer to the preoperative and intraoperative HGB values and the specific operation situation. According to the restrictive blood transfusion standard, patients who may have less than $600 \mathrm{ml}$ of blood loss do not need blood transfusions, and thus do not need to apply IBS. This is the reason why this paper analyzes the cost-effectiveness of stratified blood loss analysis.

\section{Conclusions}

In conclusion, IBS has different efficacy in different bleeding situations. Particularly, when the amount of bleeding ranges from 600 to $1000 \mathrm{ml}$, IBS can significantly reduce the demand for allogeneic blood, and has no direct adverse effects on coagulation function and postoperative recovery of patients, and is cost-effective in OPCABG under the current charge standard. The role and cost-effectiveness of using IBS in patients with old age and high-bleeding risks need to be further analyzed. Furthermore, how to accurately screen high-bleeding-risk patients is still a question worthy of study. In addition, a prospective, multi-center, randomized, controlled study is also needed to clarify the best application guidelines for IBS technology so that the technology could be applied more accurately.

\section{Abbreviations}

AB: allogeneic blood; ATLS: Advanced Trauma Life Support System; HGB: hemoglobin; IBS: intraoperative blood salvage; ICU: intensive care unit; OPCABG: off-pump coronary artery bypass grafting; PLT: platelet; RBC: red blood cell; WBC: white blood cell count

Availability of data and materials

The datasets used and/or analysed during the current study are available from the corresponding author on reasonable request.

Authors' contributions

HW designed the study, HW, WZ, WF, XL collected the data, GM, LZ, YZ, EG analyzed the data, $\mathrm{XL}$ wrote the paper. All authors read and approved the final manuscript.

\section{Ethics approval and consent to participate}

The study was approved by the Ethics Committee of the First Affiliated Hospital of Anhui Medical University.

\section{Consent for publication}

Written informed consent was obtained from each patient.

\section{Competing interests}

The authors declare that they have no competing interests.

\section{Publisher's Note}

Springer Nature remains neutral with regard to jurisdictional claims in published maps and institutional affiliations.

Received: 27 June 2018 Accepted: 25 September 2018

Published online: 17 October 2018

\section{References}

1. Malhotra A, Garg P, Bishnoi AK, Sharma P, Wadhawa V, Shah K, et al. Dialyzer-based cell salvage system: a superior alternative to conventional cell salvage in off-pump coronary artery bypass grafting. Interact Cardiovasc Thorac Surg. 2017;24(4):489-97.

2. Mehr-Aein A, Sadeghi M, Madani-civi M. Does tranexamic acid reduce blood loss in off-pump coronary artery bypass? Asian Cardiovasc ThoracAnn. 2007; 15(4):285-9.

3. Dai Z, Chu H, Wang S, Liang Y. The effect of tranexamic acid to reduce blood loss and transfusion on off-pump coronary artery bypass surgery: a systematic review and cumulative meta-analysis. J Clin Anesth. 2018; 44:23-31

4. Shafiee A, Nazari S, Mogharreban M, Koupaei MT. Evaluating medical interns' knowledge of common blood transfusion complications. Transfus Apher Sci. 2013;48(2):253-6.

5. Hassall O, Maitland K, Pole L, Mwarumba S, Denje D, Wambua K, et al. Bacterial contamination of pediatric whole blood transfusions in a Kenyan hospital. Transfusion. 2009:49(12):2594-8.

6. Sulu B, Aytac E, Stocchi L, Vogel JD, Kiran RP. The minimally invasive approach is associated with reduced perioperative thromboembolic and bleeding complications for patients receiving preoperative chronic oral 
anticoagulant therapy who undergo colorectal surgery. Surg Endosc. 2013; 27(4):1339-45.

7. Weltert L, Nardella S, Rondinelli MB, Pierelli L, De Paulis R. Reduction of allogeneic red blood cell usage during cardiac surgery by an integrated intra- and postoperative blood salvage strategy: results of a randomized comparison. Transfusion. 2013;53(4):790-7.

8. ATLS Subcommittee, American College of Surgeons' Committee on Trauma, International ATLS working group. Advanced trauma life support (ATLS(R)): the ninth edition. J Trauma Acute Care Surg. 2013;74(5):1363-6.

9. Vonk AB, Meesters Ml, Garnier RP, Romijn JW, van Barneveld LJ, Heymans MW, et al. Intraoperative cell salvage is associated with reduced postoperative blood loss and transfusion requirements in cardiac surgery: a cohort study. Transfusion. 2013:53(11):2782-9.

10. Djaiani G, Fedorko L, Borger MA, Green R, Carroll J, Marcon M, et al. Continuous-flow cell saver reduces cognitive decline in elderly patients after coronary bypass surgery. Circulation. 2007;116(17):1888-95.

11. Mutneja HR, Arora S, Vij A. Liberal or restrictive transfusion after cardiac surgery. N Engl J Med. 2015;373(2):190.

12. Karkouti K, Stukel TA, Beattie WS, Elsaadany S, Li P, Berger R, et al. Relationship of erythrocyte transfusion with short- and long-term mortality in a population-based surgical cohort. Anesthesiology. 2012;117(6):1175-83.

13. Feng S, Machina M, Beattie WS. Influence of anaemia and red blood cell transfusion on mortality in high cardiac risk patients undergoing major non-cardiac surgery: a retrospective cohort study. $\mathrm{Br}$ J Anaesth. 2017: 118(6):843-51.

14. Schwann TA, Habib JR, Khalifeh JM, Nauffal V, Bonnell M, Clancy C, et al. Effects of blood transfusion on cause-specific late mortality after coronary artery bypass grafting-less is more. Ann Thorac Surg. 2016;102(2):465-73.

15. Mazer CD, Whitlock RP, Fergusson DA, Hall J, Belley-Cote E, Connolly K, et al. Restrictive or Liberal red-cell transfusion for cardiac surgery. N Engl J Med. 2017;377(22):2133-44.

16. Shen S, Zhang J, Wang W, Zheng J, Xie Y. Impact of intra-operative cell salvage on blood coagulation in high-bleeding-risk patients undergoing cardiac surgery with cardiopulmonary bypass: a prospective randomized and controlled trial. J Transl Med. 2016;14(1):228.

17. Buys WF, Buys M, Levin Al. Reinfusate heparin concentrations produced by two autotransfusion systems. J Cardiothorac Vasc Anesth. 2016:31(1):90-98.

18. Cui $B$, Zhao $P$, Wang $C$. The different influence of inflammatory response after transfusion with autologous blood and stored blood. J Clin Anesthesiol. 2015;31(3):247-9.

19. Paladino L, Subramanian RA, Bonilla E, Sinert RH. Leukocytosis as prognostic indicator of major injury. West J Emerg Med. 2010;11(5):450-5.

20. Gu YJ, de Vries AJ, Boonstra PW, van Oeveren W. Leukocyte depletion results in improved lung function and reduced inflammatory response after cardiac surgery. J Thorac Cardiovasc Surg. 1996;112(2):494-500.

21. Xie Y, Shen S, Zhang J, Wang W, Zheng J. The efficacy, safety and costeffectiveness of intra-operative cell salvage in high-bleeding-risk cardiac surgery with cardiopulmonary bypass: a prospective randomized and controlled trial. Int J Med Sci. 2015;12(4):322-8.

22. Attaran S, Mcllroy D, Fabri BM, Pullan MD. The use of cell salvage in routine cardiac surgery is ineffective and not cost-effective and should be reserved for selected cases. Interact Cardiovasc Thorac Surg. 2011;12(5):824-6.

23. Wang G, Bainbridge D, Martin J, Cheng D. The efficacy of an intraoperative cell saver during cardiac surgery: a meta-analysis of randomized trials. Anesth Analg. 2009;109(2):320-30.

Ready to submit your research? Choose BMC and benefit from:

- fast, convenient online submission

- thorough peer review by experienced researchers in your field

- rapid publication on acceptance

- support for research data, including large and complex data types

- gold Open Access which fosters wider collaboration and increased citations

- maximum visibility for your research: over $100 \mathrm{M}$ website views per year

At BMC, research is always in progress.

Learn more biomedcentral.com/submissions 